\title{
A VIOLÊNCIA ESCOLAR NA FORMAÇÃO DOCENTE
}

\author{
SCHOOL VIOLENCE IN TEACHING TRAINING
}

LONGO, Monique Marques ${ }^{1}$

\begin{abstract}
ResUMO
Conceitos como violência escolar, homicídios, conflitos interpessoais, bullying, agressões físicas e verbais têm sido veiculadas cada vez mais, não apenas no ambiente escolar, mas nas mídias em geral. A temática faz urgir a inserção de propostas de combate ao problema, tanto nas agendas políticas como na formação docente. Mas como esses temas têm sido abordados nos cursos de licenciatura ante a iminência da problemática na escola? O presente artigo objetiva responder à questão a partir de uma pesquisa empírica realizada em seis cursos de licenciatura de três universidades cariocas, duas públicas e uma privada. São apresentadas análises de conteúdos dos seis currículos analisados e informações construídas a partir de dezenove entrevistas com alunos e professores inseridos nesses cursos. Constatou-se a superficialidade e insuficiência da temática nos cursos de formação docente assim como a eficácia de uma experiência realizada por uma disciplina constituinte de um dos cursos analisados.
\end{abstract}

Palavras-chave: Violência escolar; bullying; formação docente; licenciaturas; pensamento

\begin{abstract}
Concepts such as school violence, homicides, interpersonal conflicts, bullying, physical and verbal aggressions have been increasingly disseminated not only in the school environment but also in the media in general .The theme makes it urgent to insert proposals to combat the problem both in political agendas and in teacher education. But how have these themes been addressed in undergraduate courses before the imminence of the problem in school? This article aims to answer the question based on an empirical research carried out in six undergraduate courses of three Rio universities, two public and one private. This article aims to answer the question based on an empirical research carried out in six undergraduate courses of three universities in Rio de Janeiro, two public and one private. We present content analysis of six curricula and information from nineteen interviews with students and teachers from these courses. It was verified the superficiality and insufficiency of the subject in the teacher training courses as well as the effectiveness of an experiment carried out by a discipline constituting one of the courses analyzed.
\end{abstract}

KEYWORDS: School violence; bullying; teacher training; bachelor degrees; thought

'Doutora em Educação pela Pontifícia Universidade Católica do Rio de Janeiro (PUC- Rio), mestre em Educação pela Universidade Federal do Rio de Janeiro (UFRJ) e professora da Universidade do Estado do Rio de Janeiro (UERJ). Rio de Janeiro, RJ, Brasil. e-mail: moniqueml@globo.com 


\section{INTRODUÇÃO: QUAIS SABERES TÊM SIDO ABORDADOS NOS CURSOS DE FORMAÇÃO DOCENTE NO QUE TANGE À VIOLÊNCIA ESCOLAR?}

É fato que as diversas facetas da violência têm adentrado as escolas e desestabilizado práticas e concepções que, há tempos, têm balizado os professores. Pressupostos didáticos, métodos de ensino, saberes e práticas docentes são questionados na atualidade quando professores das diversas áreas de ensino alegam não dar conta dos seus planejamentos e objetivos curriculares devido ao tempo gasto mediando conflitos nas escolas.

Os diversos meios de comunicação, concomitante, veiculam notícias e buscam retratar episódios de massacres, homicídios, agressões físicas e psíquicas, ocorridos nos diversos âmbitos educacionais, quase que cotidianamente. A violência escolar tornou-se nas últimas décadas, salienta Debarbieux (2006, p. 23), um tema que comporta um alto grau de manipulação. O exagero midiático, as estratégias reparadoras promulgadas pelos agentes públicos e o emergente mercado de segurança nas escolas são discursos que, uma vez acionados, produzem e/ou reforçam uma "histeria da violência" em meio escolar.

Debarbieux (2006) advoga que o fenômeno teve um momento incitador: dia 12 de novembro de 1990. Nesta data, trinta e cinco mil alunos dos lycée franceses, agrediram policiais com projéteis e quebraram vitrines de lojas sob os holofotes de jornalistas. Os estudantes reivindicavam mais segurança e autoridade nas escolas. 0 fato foi midiatizado com sarcasmo e, a partir deste dia, afirma Debarbieux (2006, p. 14), "a mídia descobriu um fenômeno que não mais abandonou e que passou a ditar, de certa forma, o ritmo das agendas políticas em educação".

Ao mesmo tempo em que não se pode negar as vicissitudes que os diversos episódios violentos produzem no cotidiano das escolas, tal histeria ocasiona danos à solução da questão. Temáticas muito diversas que norteiam as violências são tratadas como semelhantes. Questões que fogem ao controle do professor, como por exemplo, os grandes massacres nas escolas americanas, são semanticamente comparadas com brigas entre alunos no recreio. Situações de agressões psíquicas dentro de sala de aula são judicializadas, enquanto o próprio professor poderia criar mecanismos para sanálas. A abrangência semântica que o conceito de violência escolar tem sido tratado pela mídia e, reverberado nas escolas, produz entraves à operacionalização de uma formação docente eficaz à mediação de conflitos interpessoais nas escolas.

Passamos a nos questionar como os futuros professores, hoje, licenciandos, matriculados nas diversas áreas da Educação, têm sido formados para lidar com a temática. Se a mediação de conflitos atravessa o cotidiano escolar, como os futuros professores estão sendo preparados para lidar com essa questão? Eles estão sendo informados sobre o problema? Que habilidades e capacidades são necessárias para mediar conflitos? A temática faz parte dos cursos de licenciatura? 
DOI: $10.12957 / \mathrm{e}-\mathrm{mosaicos} .2019 .40867$

Ante tais questões, apresentaremos uma pesquisa cujo objetivo residiu em compreender como licenciandos, futuros professores, estão sendo formados para mediarem conflitos e enfrentarem situações de violência que atravessam o cotidiano escolar.

A pesquisa, de cunho qualitativo, foi realizada em três universidades cariocas: a Universidade Federal do Rio de Janeiro (UFRJ), a Universidade do Estado do Rio de Janeiro (UERJ) e a Pontifícia Universidade Católica do Rio de Janeiro (PUC-Rio). Três Universidades renomadas e que apresentam as maiores notas gerais de avaliação dos cursos no estado do Rio de Janeiro. Nestas, avaliamos os currículos dos cursos de Filosofia e Sociologia - modalidade licenciatura - e entrevistamos três licenciandos matriculados nos seus últimos períodos. Visamos compreender como as disciplinas presentes nas grades curriculares e direcionadas à temática da violência são lecionadas e seus conteúdos abordados durante o semestre de aulas. Foram entrevistados 18 alunos e 1 professor, e os dados foram construídos com ajuda do software Atlas Ti e do método de análise de conteúdo proposto pela Laurence Bardin (1996).

\section{CURRÍCULOS DAS LICENCIATURAS E A TEMÁTICA DA VIOLÊNCIA ESCOLAR}

De posse da grade curricular dos seis cursos de licenciatura pesquisados filosofia e sociologia da UFRJ, UERJ e da PUC-Rio - observamos que eles diferem, consideravelmente, no tocante às possibilidades de abordagem da temática da violência na escola. Na PUC-Rio, encontramos um limitado número de disciplinas obrigatórias que compõem a grade da licenciatura e que pudesse abordar a questão. No entanto, os professores responsáveis pela disciplina Processo de Construção do Conhecimento na Escola e Educação e Sociedade, se balizados pelos tópicos constituintes da ementa, podem abordar em suas aulas tanto o tema da resolução de conflitos interpessoais presentes no cotidiano das escolas, quanto as suas implicações nos processos de ensino e aprendizagem. Concomitante, as disciplinas permitem que o desenvolvimento infantil e do adolescente seja debatido cujas especificidades podem fomentar a exposição das diferentes personalidades que sobressaem quando em situações de violência escolar. A temática da formação de sujeitos autônomos pode, transversalmente, nortear tais debates no decorrer dos cursos de formação de professores.

Na Faculdade de Educação da UFRJ, encontramos uma gama maior de disciplinas obrigatórias ofertadas às licenciaturas. A despeito de nenhuma intitular-se Violência Escolar, ao analisarmos as ementas das disciplinas Psicologia da Educação, Fundamentos Sociológicos da Educação e Profissão Docente, observamos que em ambas, há espaço para debates tanto sobre a temática do desenvolvimento da autonomia moral, quanto das especificidades dos conflitos interpessoais que constituem situações de violência escolar. O aluno que presencia tanto uma disciplina que aborde um viés mais sociológico da constituição dos fenômenos violentos, quanto uma outra que foque nas especificidades da formação psíquica dos sujeitos que se inserem em atos violentos poderia construir mecanismos para lidar com tais situações, 
DOI: $10.12957 / \mathrm{e}-\mathrm{mosaicos} .2019 .40867$

de forma bem fundamentada, durante os seus cursos de formação docente.

$\mathrm{Na}$ UERJ, as disciplinas obrigatórias não disponibilizam tópicos de suas ementas, para a abordagem do tema, no decorrer de seus cursos. No entanto, a Universidade demonstra uma preocupação com a temática da violência escolar ao disponibilizar três disciplinas eletivas que se direcionam à questão. Uma delas é direta ao debate e intitula-se Práticas Minimizadoras da Indisciplina e da Violência Escolar.

A ementa desta disciplina é consistente e coerente com a proposta do curso, que traça um diálogo entre tal temática e as questões inerentes ao desenvolvimento da moralidade infantil. Poucas são as eletivas ofertadas por semestre, o que nos traz indícios que muitos alunos matriculados nos diversos cursos de licenciatura presenciem tais debates no decorrer de suas formações. Além de entrevistar alunos que cursaram a disciplina, entrevistamos a professora responsável pela sua operacionalização.

\section{OS LICENCIANDOS EM FORMAÇÃO: CONCEPÇÕES E PRÁTICAS ACERCA DA VIOLÊNCIA EM MEIO ESCOLAR}

Foram entrevistados dez homens e nove mulheres na faixa etária de 19 a 59 anos. Os entrevistados tinham em média 27,8 anos. Dez entrevistados se autocaracterizaram como da raça branca, quatro pardos e cinco da raça negra. Destes negros, $40 \%$ era aluno da UERJ, $40 \%$ da UFRJ e $20 \%$ da PUC-Rio. A maioria reside em bairros da Zona Norte do Rio de Janeiro. Seis moram na Zona Sul da cidade, dois alunos moram na Zona Oeste e um entrevistado mora na cidade de Niterói. Duas entrevistadas cursaram o Ensino Médio em Escola Normal e trabalhavam com turmas de alfabetização, uma delas, há 23 anos. Cinco licenciandos realizaram o Ensino Médio em cursos técnicos e os outros 12 em cursos regulares.

As entrevistas realizadas com os estudantes se caracterizavam como semiestruturadas e, portanto, eram guiadas por uma lista de perguntas abertas que se direcionavam a compreender: (1) a abordagem da violência durante suas aulas, (2) as experiências de mediação de conflitos já vivenciadas durante os estágios e (3) como a temática da violência tem sido, ou não, abordada no cotidiano da sua formação inicial.

Quando os indagamos acerca de como enxergam a violência na escola hoje, as respostas dadas foram divergentes. Tal fato corrobora o amplo espaço semântico abarcado pelo conceito, acusado e já aqui discutido, a partir das pesquisas de Debarbieux (2006).

Podemos afirmar, concomitante, que a multiplicidade de causas expostas pelos entrevistados para a violência escolar ratifica a multicausalidade e pluralidade do fenômeno, algo afirmado por Candau, Nascimento e Lucinda (2001). A existência de uma polícia ineficiente, o aumento da pobreza, a má distribuição de renda, o desemprego e o aumento do narcotráfico na sociedade brasileira são fatores relevantes para compreender a questão. Sozinhos, entretanto, não explicam esta rotinização. A percepção destas causas depende tanto de fatores estruturais, como 
DOI: $10.12957 / \mathrm{e}-\mathrm{mosaicos} .2019 .40867$

das mediações materiais e culturais que envolvem hoje a violência na sociedade brasileira.

Seis licenciandos ressaltaram a vigência de uma violência simbólica inerente às instituições de ensino, como possível causa da violência na escolar. A própria escola seria uma instituição violenta. A forma homogeneizante de se ensinar/aprender, a forma como são estipuladas as notas, os métodos utilizados pelos professores e aqueles impostos tradicionalmente por uma cultura escolar foram ressaltados como fatores, por si só, violentos. Alguns afirmaram ainda que a repressão psíquica e física, produzida pelo sistema educacional, incita conflitos e embates no cotidiano escolar.

São ressaltadas ainda, as muitas coerções que balizam as práticas pedagógicas. Fica claro a forma autoritária de a escola se autoafirmar, algo incompatível com a concepção arendtiana de autoridade. A violência, para Arendt (2005), é gerada pela incapacidade de um poder instituído se afirmar como legítimo, e não o contrário. A violência não nasce do uso do poder, mas, justamente, do seu esfacelamento quando a autoridade vigente não é mais consensualmente aceita. Tais reflexões nos ajudam a pensar a relação da escola com a crise que, segundo Arroyo (2001), esta atravessa.

A concepção de Escola como instituição responsável pela reprodução de saberes tradicionais a serem transmitidos a todos não mais se sustenta. Tais saberes oriundos da tradição, nos lembra Arendt (2005), é colocado à prova com o advento da modernidade, abrindo espaço para um vazio que solapa instituições como a Igreja e a Escola, até então, hegemônicas. Os atores que por eles são sustentados, consequentemente, possuem sua autoridade esfacelada. E um novo questionamento surge: Da mesma forma que fez certos poderes ditatoriais, estaria a Escola, utilizandose da violência e práticas coercitivas para reivindicar seu espaço privilegiado - que se esfacelou - ante a sociedade? Certas falas, nos faz acreditar que sim.

Cara, você entra na escola é (...) tem grade. Aí toca a \#\# do sino, as crianças saem gritando, é igual o banho de sol ((risos)) Galera revoltada, revoltada. Aí tem o inspetor, tem inspetor no corredor; tem as salas no corredor, tem as celas, né?! São uns quadradinhos assim, os moleques ficam entocados lá dentro e quando põe o pé pra fora, o inspetor "pá! Vai pra dentro!". Caramba! Que \#\#\# é essa? Nossa! Vontade de correr. ((risos)) [...] A primeira vez [...] me deu vontade de sair daqui. Aí você vai acostumando, daqui a pouco tu está achando normal de novo... eles gritam, é assim mesmo... É bizarro, cara, é bizarro. Aí eles têm que aprender uma parada que eles não querem, que eles não pediram para aprender, que eles mesmos não acreditam. Isso que é triste... Tu vê que eles... muitos reproduzem os discursos de que têm que aprender para ser alguém na vida. Eles acham que não são ninguém ainda, que a escola que vai fazer deles alguém. Que \#\#\#! Que \#\#\#\#! E, cara, não tem como não gerar violência, uma violência mais prática, assim, porque é uma violência que vai gerar violência, vai gerar, não adianta. Tá numa relação absurda, tentando sustentar com o insustentável" (grifos meu) (A6). 
Seis outros entrevistados se direcionaram à desigualdade de condições e gestão, apresentada pelas escolas, como também, promotora de episódios violentos:

Os meninos comem a semana inteira arroz, feijão e ovo no almoço, Só! Não que isso seja, tipo, que vá mudar a educação com uma comida melhor, mas pelas menores coisas que a gente percebe, né, a violência já implícita aí. (...) os professores tendo que se dividir em várias escolas de um lado para o outro com os salários terríveis e pensar que essas questões geram a violência ou isso é uma violência... (...). O sistema já é violento por ele mesmo, sem falar nas violências que acontecem dentro da escola. (...) às vezes o professor que dá aula na escola pública também dá aula no São Vicente, no Teresiano, mas a aula que ele dá no Teresiano não é a mesma que ele dá na escola pública e por que isso, né? (A19).

A despeito das causas serem divergentes - alguns entrevistados alegam ser a prática pedagógica e a cultura escolar desiguais, violentas e, outros, o sistema público para com a escola pública violento - os licenciandos levantaram questões que caracterizam uma possível violência da escola, como assim classifica Charlot (2002). Segundo esse autor, para além da violência da escola - aquela promovida simbolicamente pela própria instituição - há ainda a violência na escola - gerada no seu interior por agentes externos à escola - e violência à escola - caracterizada por depredações do espaço escolar ou dos agentes que a ele pertence como professores ou coordenadores pedagógicos. Ambas são diferentes assim como devem ser as estratégias visando combatê-las.

Eu acredito que a violência também vem um pouco da questão da repressão que os alunos sofrem (...) Não poder se manifestar muito, porque cada aula exige muita atenção, exige muita concentração, enquanto os alunos devem receber informação passivamente, e não participar do processo de construção do conhecimento que a gente discute nas universidades, e que é no caso a parte teórica né, que a gente aprende, mas na parte prática acaba ocorrendo um distanciamento e as escolas ficam muito presas a conteúdos também, e isso tudo interfere, acredito neste processo de ganhar indivíduos violentos, né porque muitas vezes ele não se sente em parte deste processo de aprendizagem, se sente apenas um objeto assim, pra, talvez um número [...] não é um ambiente agradável para os alunos (A4).

No que tange à violência da escola, questões levantadas por A4 nos faz pensar sobre uma possível violência resultante do próprio processo de ensino e aprendizagem, quando este não leva em conta a necessária integração, podemos pensar em conflito, 
DOI: $10.12957 / \mathrm{e}-\mathrm{mosaicos} .2019 .40867$

do aluno com o saber. Teorias sociogenéticas assim como as de vieses mais sociointeracionistas nos aportaram quanto à imprescindibilidade da interação do aluno com seu objeto de conhecimento para que as associações e acomodações inerentes à aprendizagem aconteçam. Impedir essas inter-relações pode ser considerado também uma violência? Uma escola tradicional é violenta por natureza? Se o aprendizado, verdadeiramente, se constrói apenas quando contextualizado, significa que podemos postular que impossibilitar o aluno deste processo é em si uma violência?

Outro fator apontado por quatro entrevistados (as) como influenciador da violência presente na escola, reside em uma possível "desestruturação familiar". Para estes graduandos, mudanças ocorridas nas famílias nos últimos anos promoveram um certo descaso para com a educação dos filhos. O aumento das cargas trabalhistas, a entrada da mulher no mercado de trabalho, a "crise de valores" pela qual passa a nossa sociedade e mesmo a delegação às escolas a educação de seus filhos são apontados como causas do aumento das manifestações de violências evidentes nestas instituições, aspectos discutidos por Leme (2004), Velho e Alvito (2000) e Cardia (1997).

Agora o que eu acho em relação à violência na escola... que uma criança que nasceu, viveu em um ambiente violento, que em casa é violento, que ao redor é violento, que resolve as suas coisas com violência, que a família resolve com ela as questões com violência, eu acho que é muito difícil que na escola ela não seja violenta. Se a mãe dela é violenta com ela, se ela vê arma passando entrando num ônibus, aquilo é violento, viu. Pega um ônibus lotado, três horas para ir para o trabalho, cansado tem que ir trabalhar. Às vezes leva porrada da polícia... é assim. Não tem como achar que dentro da escola ela vai entrar e ser um anjo né? (A10).

A violência doméstica e os contextos sociais violentos, tão evidentes nas sociedades contemporâneas, aumentam, expõe Cardia (1997, p.51), "a probabilidade de fracasso escolar e de delinquência[sic] - a delinquência[...] aumenta a violência na escola e as chances de fracasso escolar, e ambos reduzem o vínculo entre jovens e a escola". Para Cardia (1997), torna-se um ciclo vicioso difícil de romper quando a família não apenas não se responsabiliza pela educação de seus filhos, mas, pior, constrói vínculos negativos, utilizando-se de formas violentas para se relacionar com seus jovens e/ou crianças.

Talvez também seja uma reprodução, um reflexo da sociedade que a gente vive também, porque os pais eles levam muita responsabilidade à escola e não se preocupam tanto com a questão da educação moral, digamos assim para com seus filhos. E o professor ele fica, acaba ficando, sobrecarregado, tendo que dar conta de meio que disciplinar os filhos dos pais ausentes ou então pais irresponsáveis (A4). 
Então o que eu vejo de violência é assim: o aluno ser tratado igual um bicho, entendeu, então ele é tratado igual um bicho em casa, é tratado igual um bicho na sala de aula e ele começa a reagir dessa maneira, entende? Aí você tem que trabalhar para que ele aja de maneira diferente (A13).

Tais falas nos trazem evidências de que a possibilidade de enfrentamento da tendência agressiva de agir, tem poucas chances de controle se, em casa e nas escolas, seus atores visualizarem um cotidiano violento. A reversão da agressividade na infância, segundo Leme (2004), acontece em função da consciência das consequências dos seus atos e da probabilidade de obter sanções pelos mesmos. Esta percepção deriva das mudanças de significado imprimido às sanções externas oriundas da disciplina dos pais e/ou outras autoridades - que por sua vez favorece a autorregulação interna do comportamento. Esta fase de desenvolvimento moral é de grande importância ao processo de regulação emocional, sobretudo, da raiva, promotora de comportamentos agressivos. Segundo Leme (2004), é fato a permeabilidade dos comportamentos violentos frente à aprendizagem. No entanto, práticas de conscientização das consequências promovidas por atos agressivos e o ensino/aprendizagem de determinados valores são imperiosos. Caso contrário, tornase quase impossível o enfrentamento da agressividade, se em locais como a casa, nas famílias e/ou escolas, reforça-se positivamente modelos violentos de comportamento.

Eu dou aula num colégio da rede estadual e que os seguranças na verdade são policiais militares que andam armados dentro do colégio. $\mathrm{O}$ que me chamou muito a atenção: porque eles andam armados dentro do colégio? Então, também, há uma preocupação no colégio no que diz respeito à violência que envolve a violência escolar, tem muito a ver naquele colégio com a violência das pessoas que moram ali naquele lugar, porque talvez participam de organização criminosa, e enfim, isso acaba indo também para dentro do colégio (A15).

Como expressou $\mathrm{A} 15$, a exposição exacerbada da violência é compreendida como um dos fatores desencadeadores da agressividade para Leme (2004). Relembramos que, para a autora, um ambiente violento favorece a produção de scripts violentos: a criança, desde cedo, constrói esquemas psíquicos organizados, abstraídos e retidos pelo sistema cognitivo favoráveis a comportamentos agressivos. O grau de repressão de emoções, como o ódio e a raiva, é socialmente construído por meio de modelos familiares ou identificações posteriores. A massificação e a visualização de modelos de comportamentos violentos fazem com que a criança compreenda que a agressão física, verbal e/ou psíquica seja a única alternativa possível para resolver situações de desavenças.

Um outro grupo de alunos compartilha, em parte, com as exposições de Velho e Alvito (2000) no que toca à violência refletir a emergência social de uma ideologia 
DOI: $10.12957 / \mathrm{e}-$ mosaicos.2019.40867

individualista desancorada de compromissos éticos. Para os autores (2000), as mudanças ocorridas entre as relações interclasses, nos últimos anos no Brasil, nas quais a lógica do clientelismo foi assumindo formas mais agonísticas e impessoais, promoveram uma ruptura com valores éticos que, até então, balizavam a sociedade brasileira. As relações desiguais de poder que foram geradas, para um grupo de entrevistados, repercutem na escola através das desiguais condições dos indivíduos acessarem os diversos produtos sociais, culturais e de consumo. Tais disparidades, muitas vezes, favorecem práticas violentas e a agressão como modelo único de ação.

A violência é oriunda da sociedade em que a gente vive. Eu creio que se existe violência, é porque a gente vive num país que tem um uma desigualdade social muito grande.(...) A desigualdade social gera a questão de: um aluno ter, outro não ter; um aluno poder, outro não poder; um aluno estar fora dos padrões, o outro, nos padrões (A2).

Dois entrevistados atrelaram a violência escolar às dificuldades enfrentadas pelos adolescentes no caminho de formação identitária. Dois licenciandos defenderam ser a necessidade de se autoafirmar como sujeito ante seus pares, seu grupo de amigos e as dificuldades enfrentadas no decorrer desta construção a maior causa da manifestação do agir violento.

A adolescência é uma fase muito difícil (...) porque é um momento que ele precisa se autoafirmar. Então, gera uma violência psicológica, mas eu acho que esta violência psicológica acaba gerando uma violência física, em parte por causa da questão da diferença e/ou da indiferença... (A2).

É que a gente vive tão oprimido, vive sem condições de, de... de nada, né? Tem pessoas que passam fome, né? Não nascem em uma família bem estruturada... é... a política... os políticos corruptos, né? Tem a questão também de você querer ser e não poder... Então, acho que isso tudo é uma resposta, né?... (A8).

Tais discursos retratam as vicissitudes enfrentadas pelos adolescentes ao se constituírem como sujeitos autônomos, mas também, a falta de compreensão dos licenciandos acerca de como tal amadurecimento ocorre, fato necessário para se trabalhar com tal faixa etária. Podemos pensar que na sociedade contemporânea as formas de se constituir sujeitos são diversas. De forma díspar às limitadas oportunidades oferecidas pela sociedade moderna - onde os caminhos eram já préestipulados, sobretudo, pelos preâmbulos de gênero e classe - hoje, abre-se um leque de escolhas e vetores possíveis à constituição identitária. Ao mesmo tempo em que possibilita uma gama ampla de possibilidades, tal multiplicidade provoca uma profunda sensação de insegurança. Sensação, muitas vezes, incitadora das atitudes que os 
DOI: $10.12957 /$ e-mosaicos.2019.40867

entrevistados conceituam como "autoafirmativas".

Num segundo momento da entrevista, direcionamos nossas indagações às suas experiências vigentes. Perguntamo-nos se vivenciaram algumas situações violentas durante seus estágios.

Alguns entrevistados disseram ter vivenciado, mesmo no limitado tempo e espaço dos estágios, algumas situações balizadas por preconceitos, não aceitação das diferenças e /ou necessidade de se afirmar ante um grupo social. Foi relatado um caso em que a professora foi chamada de prostituta, outro de duas brigas entre alunos, um caso de uma diretora que cuspiu na aluna, outro de duas brigas entre alunas e professor por conta de nota e o caso de uma mãe afirmar que a professora era incapaz de gerir a escola por utilizar cadeira de rodas.

Eu vivenciei uma sim, porque a diretora de um dos colégios onde eu estagiei era deficiente física, e uma mãe, que não era aluna, ao brigar com a diretora, xingou ela de... bom, xingamentos para pessoas deficientes que eu prefiro não designar... os xingamentos. Mas xingou ela, disse que uma pessoa assim não poderia estar na direção (A16).

Dois casos de violência foram relatados pelos estagiários e considerados marcantes para a formação destes: um caso de esfaqueamento em que a diretora se eximiu da responsabilidade, e outro em que o professor, por ser contratado temporariamente, fingia não entender o preconceito demonstrado pelos alunos.

Tem um caso que é o mais assim, que mexe até profundamente comigo, que uma aluna foi esfaqueada no Projovem lá no... eu dava aula numa escola no Morro do Pinto, e ela foi esfaqueada. Ela levou, sei lá, dez facadas nas costas (A9).

Os alunos, eles não gostavam do professor pelo fato dele ser nordestino, inclusive criavam apelidos para ele e tal. Ou seja, eles desrespeitavam só pelo fato dele ser nordestino (A15).

No momento final da entrevista, objetivamos compreender como a temática da violência escolar é abordada durante os cursos de formação docente. A partir das experiências vivenciadas durante os estágios e, a mim, relatadas, questionei se a temática havia sido problematizada e como havia sido sua operacionalização. A maioria dos entrevistados se dividiu em duas remissivas respostas. Seis graduandos responderam que durante algumas disciplinas houve debates, mas se limitavam à violência social, em termos gerais. Inferimos que direcionado às especificidades da problemática nas escolas não houve abordagem de conteúdos. Outros seis alegaram haver a abordagem, mas apenas quando os alunos indagavam seu agir frente às situações que vivenciaram no estágio.

Não. Uma hora ou outra a gente toca em algum tema mais polêmico, 
porque, na verdade, na minha turma, eu sou a que tenho um contato direto com a educação. Então, como eu tenho um pouco mais de experiência, e às vezes eu puxo tema, algum relato de alguma coisa que aconteceu, porque eu acho que seria interessante discutir (A7)

Inferimos das respostas apresentadas que a questão era abordada ocasionalmente e que não havia um planejamento e/ou um organização acerca de uma possível proposta temática para as aulas, o que nos remete às respostas explicitadas pelo segundo grupos de entrevistados. Quatro licenciandos alegaram haver um debate sobre a temática, mas realizado de forma muito superficial e desligado de qualquer aporte teórico mais elaborado. A discussão sobre a violência escolar, quando surge, norteia-se pelo senso comum e ditames não teoricamente fundamentados. Quando questionados se presenciaram alguma aula direcionada exclusivamente à violência escolar, responderam:

Não. A gente tava até discutindo isso (violência escolar) numa aula; foi até a aula da Maria. A gente tava discutindo os tipos de escola, os tipos de escola técnica, clássica... (...) os modelos pedagógicos e num debate desse a gente discutiu sobre as questões da violência escolar e coisas sobre o estágio de campo lá, e a gente tinha que ver no estágio de campo como estavam acontecendo as práticas e relacionar com... era parte do relatório final. Isso a gente abordou, falou algumas coisas nesta aula, mas também não foi assim.... não era o tema central da discussão (A18).

É coisa de tipo assim, o professor começou a falar, alguém levanta a mão e fala. Não é uma discussão, não tem nada planejado, não tem texto nenhum, nada. (...) É uma discussão bem senso comum (A20).

Três alunos matriculados na UERJ alegaram estar presente nos seus currículos uma disciplina direcionada especificamente à temática da violência - algo já observado na análise dos currículos na primeira parte da pesquisa de campo.

O tema foi abordado justamente a partir da perspectiva das questões do preconceito, que são sempre presentes, do modo como a gente deve lidar com esses alunos enquanto educadores, para que a gente também possa minimizar a violência e a indisciplina. Eu lembro que essa disciplina trazia muitas dinâmicas.(...) Basicamente se eu pudesse dizer para você como essas aulas se desenvolveram, se elas se desenvolveram a partir de textos ou da discussão, não, não foram, foram a partir das dinâmicas que envolviam sempre essa questão do sentir mesmo, do vivenciar, mesmo que seja de maneira... através de uma simulação, o que seria essa indisciplina, o que seria essa violência. (...). Então o que ele nos ensinava era justamente a observar, a ter a sensibilidade para perceber (A15). 
Olha, a aula inicialmente navegou por algumas discussões mais técnicas, Vygotsky, Piaget, desenvolvimento do conhecimento; e trabalhou muito mais o reforço de que a violência física não é o único problema, é só uma parte. A violência simbólica e verbal seria a mais comum de se verificar hoje em dia, onde você tem uma proibição maior da violência física, mas você tem um certo descontrole das violências simbólicas. Aí também, o professor acabou indo na direção do colégio, como sendo um símbolo direto dessa violência; ou então quando você reprova o aluno, você estaria com a prática da violência... (A16).

São matérias assim, que tem vários turnos, então tem vários professores assim...(...) Eu cheguei até me inscrever, porque é única... é uma eletiva obrigatória praticamente. São poucas vagas, aliás poucas vagas, poucos horários apesar de ter uns sete horários para o pessoal de Educação, mas ela enche muito. Ela é uma disciplina que é única eletiva, eu acho. Uma das únicas. São três delas. Uma de cotidiano escolar, essa de violência e indisciplina e uma outra que agora eu não tô recordando o nome que elas são disciplinas obrigatórias de educação e como ela atende a faculdade toda acaba nunca tendo... poucas pessoas conseguem as vagas. Sei lá, eu acho que tem 20, 15 vagas e sei lá, e tem uma concorrência de 90 pessoas. Aí ficam lotadas as turmas. Eu já tentei umas seis vezes essa disciplina. Esse semestre eu tentei de novo e ainda não entrei (A18).

O depoimento de A15 ratifica a relevância da metodologia adotada pelo professor. O aluno ressaltou que a disciplina teve um impacto na sua formação tanto por ela ter sido dada em forma de dinâmicas - o que demonstra certa preocupação de que as reflexões surgissem de situações práticas -, como por ela não ter se limitado a transmitir um tipo de fórmula pronta.

Junto à ementa do curso, inferimos que sua operacionalização estava coerente com a proposta curricular. No entanto, a observação feita por A18 referente às poucas vagas oferecidas corrobora a pouca abrangência desta aos licenciandos que se formam nesta IES. Por outro lado, observamos a grande procura pela disciplina, o que também ratifica a necessidade e a relevância de que a discussão sobre a temática da violência aconteça no decorrer dos cursos de formação docente.

Ficou claro um caminho que se descortina ao se buscar enfrentar os desafios impostos pela violência escolar por meio de uma disciplina curricular que dialogue com as experiências práticas com uma coerente fundamentação teórica. Diferente de apresentar fórmulas prontas, universalizáveis, oportunizar um espaço para significar estas experiências, um espaço-tempo para o pensar, mostrou-se um caminho para que os próprios licenciandos criem suas estratégias cotidianamente, aportados teoricamente.

E eu acho que a postura do professor pode ser um ponto de partida, porque muitos colocam sempre "o aluno é violento, a escola não sei o 
que, e você? Você não é violento também?". (...). E foi interessante, porque eles começaram a falar sobre eles mesmos, dando exemplos de si próprios, de colegas, seguindo nesse processo, porque eu quero trazer o aluno para dentro do processo, sabe, ele é professor, ele é ser humano, ele tem instintos (A15).

\section{ALgUMAS CONSIDERAÇÕES POSSÍVEIS}

Relembramos que o texto direcionou-se a apresentar tanto uma discussão teórica, acerca das vicissitudes que têm atravessado as recentes discussões sobre o fenômeno da violência escolar, quanto analisar dados de uma pesquisa empírica, realizada em seis cursos de licenciatura localizados na cidade do Rio de Janeiro.

Quanto ao primeiro objetivo, tornaram-se claros os desafios enfrentados quando buscamos distinguir o termo violência de outros que são utilizados como sinônimos. Aportados teoricamente em Debarbieux (2006), vivenciamos uma "histeria midiática" em relação à violência ocorrida em ambientes escolares. A exacerbação de episódios pontuais de massacres e homicídios, veiculados de forma sensacionalista, fomenta a judicialização de casos que poderiam ser evitados pela própria escola se refletissem estratégias para mediarem conflitos. Debarbieux (2006) e Charlot (2001) nos orientaram quanto às distinções existentes entre os termos violência escolar e agressividade, transgressões, incivilidades e agressões, assim como, entre as violências das escolas, violências à escola, e violência na escola. Ante eles, ficou claro que o uso indistinto e não rigoroso dos termos fomenta a sua utilização como categoria segregadora de alunos que não sustentam o padrão estipulado - fato que por sua vez pode se tornar mote de episódios conflituosos na escola. Desta forma ainda, podemos pensar até que ponto ficamos impossibilitados de estipular estratégias de enfrentamento da questão que vem, cada vez mais, inviabilizando os processos de ensino e aprendizagem.

Nossa pesquisa empírica ratificou a insuficiente abordagem da temática nos atuais cursos de licenciatura, cuja taxa de abandono chega a 75\% (INEP/MEC). Nos seis cursos de licenciatura analisados, há apenas uma disciplina exclusivamente direcionada à discussão do fenômeno presente no cotidiano dos próprios licenciandos quando iniciam seus estágios supervisionados. A despeito de todos os alunos entrevistados ressaltarem experiências de indisciplina e até atos de violência durante suas iniciais práticas pedagógicas e afirmarem sentirem-se inseguros para lidar com tais questões, apenas uma disciplina eletiva, com pouco número de vagas, é ofertada aos alunos de uma das IES analisadas.

Os alunos que cursaram Práticas Minimizadoras da Indisciplina e da Violência Escolar na UERJ corroboraram a importância e o impacto que tais discussões tiveram na sua formação, sobretudo, pela disciplina nortear-se por questões práticas levantadas a partir do próprio questionamento discente. Um aporte teórico consistente, balizado por referenciais da psicologia da aprendizagem e do desenvolvimento assim como de sociólogos que debatem o fenômeno de forma 
DOI: $10.12957 / \mathrm{e}-\mathrm{mosaicos} .2019 .40867$

multicausal e multiestrutural mostrou-se, ainda, de grande relevância às necessidades práticas apresentadas pelos licenciandos.

Findamos almejando contribuir com a discussão de um tema que muito tem desafiado tanto pesquisadores, como professores, inseridos nos diversos espaços educativos. A despeito da inexistência de um consenso ao significarmos as violências em meio escolar, ficam claros os impasses que se descortinam ao utilizarmos o termo de forma não rigorosa, mesmo dentro dos cursos de formação docente. Acreditamos, por fim, que o caminho rumo ao seu enfrentamento é longo, porém, pensar práticas de enfrentamento da temática, sobretudo, desde a formação inicial docente, mostrase um primeiro passo.

\section{REFERÊNCIAS}

ARENDT, H. Sobre a violência. Rio de Janeiro: Civilização Brasileira, 2005.

ARROYO, M. Quando a violência infanto-juvenil indaga a pedagogia. Revista Educação e Sociedade. 28,100, p. 787-807, 2001.

BARDIN, L. L'Analyse de contenut. Collection Le Psychologue. 8.ed. Paris: Corrigée PUF, 1996.

CANDAU, V.; LUCINDA, M. da C.; NASCIMENTO, M. das G. Escola e violência. 2. ed. Rio de Janeiro: DP \& A, 2001.

CARDIA, N. Violência urbana e a Escola. In: Revista contemporaneidade e educação. Rio de Janeiro, IEC, ano II, n. 2, p. 26-69, 1997.

CAVACO, M.H. Ofício de professor: o tempo e as mudanças. In NOVOA, A. (Org.) Profissão Professor. Portugal: Porto, 1993.

CHARLOT, B. A violência na escola: como os sociólogos franceses abordam essa questão. Sociologias, 8, 4, p.8-16, 2002.

DEBARBIEUX, E. A violência na escola francesa: 30 anos de construção de um objeto (1967 -1997). Educação e Pesquisa, 27, 1, 2001.

. Violência na escola: um desafio mundial? Lisboa: Instituto Piaget, 2006.

GABARDO, C., HOBOLD, M. Início da docência: investigando professores do ensino fundamental In Revista Brasileira de pesquisa sobre a formação de professores. Vol 3 número 5, dez de 2011.

HUBERMAN, M. Ciclo de vida profissional dos professores In: NOVOA, A (Org). Vidas de professores. 2. ed. Portugal: Porto Editora, p. 31-61, 1992. 


\section{INSTITUTO NACIONAL DE ESTUDOS E PESQUISAS EDUCACIONAIS (INEP)/} MINISTÉRIO DA EDUCAÇÃO (MEC). Estudo exploratório sobre o professor brasileiro: com base nos resultados do Censo Escolar da Educação Básica, Brasília, DF: MEC/INEP, 2009.

LEME, M. I. S. Resolução de conflitos interpessoais: interação entre cognição e afetividade na cultura In: Psicologia: Reflexão e critica, 17 (3), p. 367-380, 2004.

MARCELO, C. A formação de professores: centro de atenção e pedra-de-toque. In: NOVOA, A. Os professores e a sua formação. Lisboa: Dom Quixote, 1992.

TARDIF, M. Saberes docentes e formação profissional. Petrópolis, RJ: Vozes, 2002. VELHO, G e ALVITO, M. Cidadania e Violência. Rio de Janeiro: Ed. UfRJ, 2000.

Recebido em 18 de março de 2019 Aceito em 13 de junho de 2019

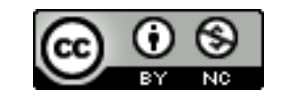

A e-Mosaicos Revista Multidisciplinar de Ensino, Pesquisa, Extensão e Cultura do Instituto de Aplicação Fernando Rodrigues da Silveira (CAp-UERJ) está licenciada com uma Licença Creative Commons - Atribuição-NãoComercial 4.0 Internacional.

Os direitos autorais de todos os trabalhos publicados na revista pertencem ao(s) seu(s) autor(es) e coautor(es), com o direito de primeira publicação cedido à e-Mosaicos.

Os artigos publicados são de acesso público, de uso gratuito, com atribuição de autoria obrigatória, para aplicações de finalidade educacional e não-comercial, de acordo com o modelo de licenciamento Creative Commons adotado pela revista. 